American Journal of Applied Sciences 6 (11): 1902-1908, 2009

ISSN 1546-9239

(C) 2009 Science Publications

\title{
The Effect of Buoyancy Force in Computational Fluid Dynamics Simulation of a Two-Dimensional Continuous Ohmic Heating Process
}

\author{
${ }^{1}$ Elzubier A. Salih, ${ }^{1}$ Thomas S.Y. Choong, ${ }^{2}$ S.Y. Sergie, ${ }^{3}$ N.L. Chin and ${ }^{4}$ O.M. Ibrahim \\ ${ }^{1}$ Department of Chemical and Environmental Engineering, Faculty of Engineering, \\ University Putra Malays, 43400, Serdang, Selangor DE, Malaysia \\ ${ }^{2}$ Faculty of Engineering, Nottingham University, Malaysia \\ ${ }^{3}$ Department of Process and Food Engineering, Faculty of Engineering, \\ University Putra Malaysia, 43400, Serdang, Selangor DE, Malaysia \\ ${ }^{4}$ Department of Food System, College of Food and Agriculture, \\ United Arab Emirates University, UAE
}

\begin{abstract}
Problem statement: Earlier work on ohmic heating technique focused on viscous food and foods containing solid particles. In this study, the use of ohmic heating on sterilization of guava juice is carried out. Computational fluid dynamics is used to model and simulate the system. Approach: Investigate the buoyancy effect on the CFD simulation of continuous ohmic heating systems of fluid foods. A two-dimensional model describing the flow, temperature and electric field distribution of non-Newtonian power law guava juice fluid in a cylindrical continuous ohmic heating cell was developed. The electrical conductivity, thermo physical and rheological properties of the fluid was temperature dependent. The numerical simulation was carried out using FLUENT 6.1 software package. A user defined functions available in FLUENT 6.1 was employed for the electric field equation. The heating cell used consisted of a cylindrical tube of diameter $0.05 \mathrm{~m}$, height $0.50 \mathrm{~m}$ and having three collinear electrodes of $0.02 \mathrm{~m}$ width separated by a distance of $0.22 \mathrm{~m}$. The sample was subjected to zero voltage at the top and bottom of electrodes while electrical potential of 90 volts (AC $50-60 \mathrm{~Hz}$ ) was set at the middle electrode. The inlet velocity is $0.003 \mathrm{~m} \mathrm{sec}^{1}$ and the temperature is in the range of $30-90^{\circ} \mathrm{C}$. Results: The simulation was carried with and without buoyancy driven force effect. The ohmic heating was successfully simulated using CFD and the results shows that the buoyancy has a strong effect in temperature profiles and flow pattern of the collinear electrodes configuration ohmic heating. A more uniform velocity and temperature profiles were obtained with the buoyancy effect included. Conclusion: For accurate results, the inclusion of buoyancy effect into the CFD simulation is important.
\end{abstract}

Key word: CFD numerical modeling, 2D ohmic heating, Natural convection, guava juice

\section{INTRODUCTION}

Ohmic heating is a developing technology with considerable potential for the food industry. The main advantages of ohmic processing are the rapid and relatively uniform heating achieved, together with the lower capital cost compared to other electro heating methods such as microwave and radio frequency heating. Ohmic heating technology has been accepted by the industry for processing liquids and solid liquid mixtures $^{[1]}$. In the absence of a hot wall, ohmic heating provides a considerable advantage for foodstuff applications, by not only avoiding the degradation of thermo-sensitive compounds through over-heating but also by reducing the fouling of treated food surfaces during processing ${ }^{[2]}$.

The potential applications of ohmic heating technique in food industry are very wide, e.g., blanching, evaporation, dehydration and pasteurization ${ }^{[3]}$. Earlier work focused on viscous food and foods containing solid particles. The most critical property affecting ohmic heating rate is food electrical conductivity. The electrical conductivity is affected by parameters such as temperature, ionic strength, free water and material microstructure ${ }^{[4]}$.

Corresponding Author: Thomas S.Y. Choong, Department of Chemical and Environmental Engineering, Universiti Putra Malaysia, 43400 Serdang, Malaysia Fax: +603-8656-7120 
Computational Fluid Dynamics (CFD) is a state of the art numerical technique for solving fluid flow problems. CFD calculations use a computational grid to solve the governing equations describing fluid flow, i.e., the continuity, momentums and energy equations and additional conservation equations, such as electrical field equations, across each grid cell by means of an iterative procedure in order to predict and visualize the profiles of velocity, temperature, pressure. Early users of CFD are found in the automotive, aerospace and nuclear industries. With the enhancement of computing power and efficiency and the availability of affordable CFD packages, applications of CFD have extended into the food industry for modeling industrial processes, thereby generating comprehensive analysis leading to design of more efficient systems ${ }^{[5]}$.

Guava (Psidium guajava L., family Myrtaceae) is a popular fruit tree of the tropics and subtropics and is important in international trade and domestic economy of several countries in warmer climates. Guava fruit is rich in vitamin $\mathrm{C}$ and also a good source of pectin ${ }^{[6]}$. The guava can be consumed fresh or can be processed into juices, pulps, jams, jellies or dehydrated products, as well as being used as an additive to other fruit juices or pulps ${ }^{[7]}$.

Conventional pasteurization requires long heating time leading to deterioration of product quality. Electromagnetic heating, on the other hand, has been successfully used for efficient pasteurization of food products in the recent years ${ }^{[8]}$. However most of the studies have concern over the sterilization of food products containing particles ${ }^{[9-14,19]}$. There are only a few scientific and technical studies dedicated to continuous fluid treatment by ohmic heating ${ }^{[15-16]}$.

The objective of this study is to model and simulate an axisymmetric two-dimensional cylindrical continuous ohmic heating system and to investigate the effect of buoyancy force on velocity profiles, temperature profiles and current density of the ohmic heating system.

\section{MATERIALS AND METHODS}

The ohmic heating cell: The ohmic heating cell used in this study is shown in Fig. 1. It consists of a cylindrical tube $0.05 \mathrm{~m}$ in diameter and $0.5 \mathrm{~m}$ in height. Three electrodes $(0.02 \mathrm{~m}$ thick) are fixed at distance of $0.22 \mathrm{~m}$ from one another. It operates at an inlet velocity $0.003 \mathrm{~m} \mathrm{sec}^{-1}$ and a temperature range of $30-90^{\circ} \mathrm{C}$. Power connection was from $90 \mathrm{~V}$, single-phase AC line.

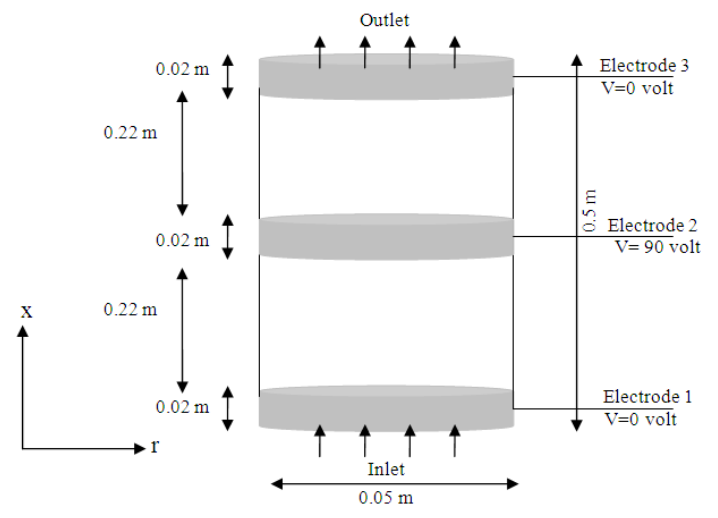

Fig. 1: Schematic ohmic heating cell of collinear electrodes

Table 1: Properties and parameters used in simulations

\begin{tabular}{lll}
\hline Properties and parameters & Value/expression & Units \\
\hline Consistency index $(\mathrm{K})$ & $\mathrm{K}=0.117$ & $\mathrm{~Pa} \mathrm{~s}^{\mathrm{n}}$ \\
Flow behavior index $(\mathrm{n})$ & $\mathrm{n}=0.5978$ & Dimensionless \\
Density $(\rho)$ & $\rho=1041.1-0.6896 \mathrm{~T}$ & $\mathrm{~kg} \mathrm{~m}^{-3}$ \\
Thermal conductivity $(\mathrm{k})$ & $\mathrm{k}=0.4401+0.0039 \mathrm{~T}$ & $\mathrm{~J} \mathrm{~m}^{-1}{ }^{-1} \mathrm{C}^{-1}$ \\
Specific heat $\left(\mathrm{C}_{\mathrm{p}}\right)$ & $\mathrm{C}_{\mathrm{p}}=4035.7+17.935 \mathrm{~T}$ & $\mathrm{~J} \mathrm{~kg}^{-1} \mathrm{C}^{-1}$ \\
Electrical conductivity $(\sigma)$ & $\sigma=0.0038 \mathrm{~T}+0.0642$ & $\mathrm{~S} \mathrm{~m}^{-1}$ \\
Viscosity at $30^{\circ} \mathrm{C}\left(\mu_{\text {ref }}\right)$ & 0.013 & $\mathrm{~Pa} \mathrm{~s}^{\circ}$ \\
Density at $30^{\circ} \mathrm{C}\left(\rho_{\text {ref }}\right)$ & 1019 & $\mathrm{~kg} \mathrm{~m}^{-3}$ \\
Inlet velocity $\left(\mathrm{v}_{\mathrm{m}}\right)$ & 0.003 & $\mathrm{~m} \mathrm{~s}^{-1}$ \\
Coefficient of volume expansion $(\beta)$ & 0.00051 & $1 /{ }^{\circ} \mathrm{C}$ \\
Reference electrical conductivity $\left(\sigma_{0)}\right)$ & 0.00383 & $\mathrm{~S} \mathrm{~m}{ }^{-1}$ \\
Diameter of the heating cell $(\mathrm{D})$ & 0.05 & $\mathrm{~m}$ \\
Distance between electrodes $\left(D_{\mathrm{e})}\right.$ & 0.22 & $\mathrm{~m}$ \\
Inlet temperature $\left(T_{\text {ref }}\right)$ & 30 & ${ }^{\circ} \mathrm{C}$ \\
Applied voltage $(V)$ & 90 & $\mathrm{Volt}$ \\
\hline
\end{tabular}

Applied voltage $(\mathrm{V})$

Sample preparation: Guava juice was prepared from pink Guava purees which was obtained from Golden Hope Fruit Industries (M) Sdn., Malaysia and was diluted by adding distilled water in a volumetric ratio of 1:3 (v/v). The temperature dependent rheological and thermo physical properties of the sample were measured and were shown in Table 1.

Governing equations: The flow is axisymmetric about the center line which makes the problem two dimensional instead of three dimensional. The governing conservation equations and the boundary conditions in continuous ohmic heating are formulated with the following assumptions:

\section{Assumption:}

- Incompressible, steady state, laminar flow

- Heat generation due to viscous dissipation is negligible

- No heat loss and mass flow through cylinder wall and that the tube is insulated 
- Small axial conduction compared to radial conduction

- The wall of the heating cell is electrically insulated, implies that no voltage gradient across the wall

- Boussinesq approximation is valid, i.e., the density difference, which causes the flow, has a linear relationship with temperature

- No-slip condition at the inside wall of the heating cell

- At the entrance of the heating cell, the flow has uniform temperature and uniform velocity

- The fluid rheological and thermo physical properties are temperature dependent

Continuity equation: The continuity equation is given by:

$\frac{1}{\mathrm{r}} \frac{\partial}{\partial \mathrm{r}}\left(\mathrm{rv}_{\mathrm{r}}\right)+\frac{\partial \mathrm{v}_{\mathrm{x}}}{\partial \mathrm{x}}=0$

where, $v_{r}$ and $v_{x}$ is the fluid velocity in the radial and axial directions, respectively.

Momentum conservation equations in $x$-direction: Considering a vertical cylindrical heating cell in which electrodes are inserted, the momentum equation for the vertical velocity $\mathrm{v}_{\mathrm{x}}$ in cylindrical coordinates is expressed by:

$$
\begin{aligned}
\rho\left(\mathrm{v}_{\mathrm{r}} \frac{\partial \mathrm{v}_{\mathrm{x}}}{\partial \mathrm{r}}+\mathrm{v}_{\mathrm{x}} \frac{\partial \mathrm{v}_{\mathrm{x}}}{\partial \mathrm{x}}\right)= & -\frac{\partial \mathrm{p}}{\partial \mathrm{x}}+\rho_{\text {ref }}\left[1-\beta\left(T-\mathrm{T}_{\text {ref }}\right)\right] \mathrm{g}_{\mathrm{x}} \\
& +\frac{1}{\mathrm{r}} \frac{\partial}{\partial \mathrm{r}}\left(\mu_{\mathrm{a}} \mathrm{r} \frac{\partial \mathrm{v}_{\mathrm{x}}}{\partial \mathrm{r}}\right)+\frac{\partial}{\partial \mathrm{x}}\left(\mu_{\mathrm{a}} \frac{\partial \mathrm{v}_{\mathrm{x}}}{\partial \mathrm{x}}\right)
\end{aligned}
$$

In this study, the Boussinesq approximation was used to account for the buoyancy force driving the convective motion of the fluid ${ }^{[17]}$. The density is assumed constant in the governing equations except in the buoyancy term (Boussinesq approximation).

\section{Momentum conservation equation in r-direction:}

$\rho\left(v_{r} \frac{\partial v_{r}}{\partial r}+v_{x} \frac{\partial v_{r}}{\partial x}\right)=-\frac{\partial p}{\partial r}+\left[\frac{\partial}{\partial r}\left(\frac{1}{r} \frac{\partial}{\partial r}\left(\mu_{\mathrm{a}} \mathrm{rv}_{\mathrm{r}}\right)\right)+\frac{\partial^{2} \mathrm{v}_{\mathrm{r}}}{\partial \mathrm{x}^{2}}\right]$

The viscosity of guava juice is found to decrease with an increase in shear rate and its flow behavior can be expressed using a power-law model which is given as follows:

$$
\tau_{\mathrm{ry}}=\mathrm{K}\left(-\frac{\partial \mathrm{v}_{\mathrm{x}}}{\partial \mathrm{r}}\right)^{\mathrm{n}}
$$

and

$$
\mu_{\mathrm{a}}=\mathrm{K}\left(-\frac{\partial \mathrm{v}_{\mathrm{x}}}{\partial \mathrm{r}}\right)^{\mathrm{n}-1}
$$

Where:

$\tau_{\mathrm{ry}}=$ Represents the shear stress $(\mathrm{Pa})$ in the r-direction and the negative sign indicates the shear stress occurs in the direction of decreasing velocity

$\mathrm{K}=$ The consistency coefficient $\left(\mathrm{Pa} \mathrm{s}^{\mathrm{n}}\right)$

$\mathrm{n}=$ The flow behavior index

$\gamma=$ The shear rate $\left(\sec ^{-1}\right)$

$\mu_{\mathrm{a}}=$ The apparent viscosity ( $\left.\mathrm{Pa} \mathrm{s}\right)$

Both the consistency coefficient $(\mathrm{K})$ and flow behavior index $(\mathrm{n})$ are temperature dependent.

Considering the effect of electrical field on gravityinduced free convection, the conventional Grashof number is modified by replacing $g$ with $\frac{E^{2} b}{D}{ }^{[18]}$ :

$\mathrm{Gr}_{\mathrm{El}}=\frac{\rho^{2} \beta \Delta \mathrm{TD}^{2} \mathrm{E}^{2} \mathrm{~b}}{\mu^{2}}$

where, $\mathrm{Gr}_{\mathrm{El}}$ is the electrical Grashof number.

Energy conservation equation: The thermal behavior is based on the energy balance. It includes convection, conduction and heat generation, given by:

$\rho C_{p}\left(v_{r} \frac{\partial T}{\partial r}+v_{x} \frac{\partial T}{\partial x}\right)=\frac{1}{r} \frac{\partial}{\partial r}\left(k r \frac{\partial T}{\partial r}\right)+Q$

Electric field distribution equation: The Laplace equation for electric field distribution was solved in the whole fluid at steady state and it is dependent on the temperature distribution. In cylindrical coordinates, the electric field distribution of the spacing tube between the two electrodes can be calculated from ${ }^{[10]}$ :

$\frac{\partial}{\partial x}\left(\sigma \frac{\partial V}{\partial x}\right)+\frac{1}{r} \frac{\partial}{\partial r}\left(r \sigma \frac{\partial V}{\partial r}\right)=0$

The heating rate is directly proportional to the electrical conductivity and the square of the electric field strength ${ }^{[10]}$ :

$\mathrm{Q}=\sigma(\nabla \mathrm{V} \cdot \nabla \mathrm{V})=|\nabla \mathrm{V}|^{2} \sigma$ 
Boundary conditions: The boundary conditions are:

- At symmetry $\mathrm{r}=0, \frac{\partial \mathrm{T}}{\partial \mathrm{r}}=0, \frac{\partial \mathrm{v}_{\mathrm{x}}}{\partial \mathrm{r}}=0, \frac{\partial \mathrm{V}}{\partial \mathrm{r}}=0 \quad$ and $\mathrm{v}_{\mathrm{r}}=0 \mathrm{~m} \mathrm{sec}^{-1}$, for $0 \leq \mathrm{x} \leq \mathrm{L}$

- At the wall, $\frac{\partial \mathrm{T}}{\partial \mathrm{r}}=0, \frac{\partial \mathrm{v}_{\mathrm{x}}}{\partial \mathrm{r}}=0, \frac{\partial \mathrm{V}}{\partial \mathrm{r}}=0$ and $\mathrm{v}_{\mathrm{x}}=\mathrm{v}_{\mathrm{r}}=0$ $\mathrm{m} \sec ^{-1}$ For $0 \leq \mathrm{x} \leq \mathrm{L}$ at $\mathrm{r}=\mathrm{R}$

The wall was assumed insulated except at the electrodes, the voltage at bottom and top electrodes $=0$ and at the middle electrode $=90 \mathrm{~V}$.

At inlet at $\mathrm{x}=0 \mathrm{~m} . \mathrm{V}=0$ volt, $\mathrm{v}_{\mathrm{x}}=0.003 \mathrm{~m} \mathrm{sec}^{-1}$, $\mathrm{v}_{\mathrm{r}}=0 \mathrm{~m} \mathrm{sec}^{-1}$ and $\mathrm{T}=30^{\circ} \mathrm{C}$ at $0 \leq \mathrm{r} \leq \mathrm{R}$.

Numerical approach: A commercial Computational Fluid Dynamics (CFD) package FLUENT (v 6.1, Fluent, Inc. India) is used to solve the governing partial differential equations with appropriate boundary conditions. A user defined functions available in FLUENT was adopted to solve the electric field equation. Structured meshing scheme was generated using GAMBIT pre-processor (v 2.0 Fluent, Inc. India). Grids created with GAMBIT were then read and checked in FLUENT to make sure that all the volumes created are positive. Operating conditions and boundary conditions were specified, as well as the properties of fluid present in the system. For a better control of solution, different algorithms were selected and the level of convergence desired by the user was selected. Before starting to iterate, properties of the flow field such as velocity temperature and viscosity parameters were initialized from a specified boundary. The segregated solver was chosen as the numerical solution method. This approach segregates the governing equations and solves them sequentially. In addition, the governing equations are non-linear and consequently required several iterations of the solution loop to be performed.

Because of symmetry, only half of the $2 \mathrm{D}$ ohmic heating cell geometry needs to be modeled. A regular, structured grid of hexahedral mesh elements was created to discretize the domain using 231876 elements. The adaptive refinements of meshes were automatically added for better solution resolution.

The CFD simulations were performed in the computer system intel/2R, $2.85 \mathrm{GHz}$ and 3GB RAM machine running on WINDOWS 2002 Professional. The computer processing time required was about 40 min for simulating the temperature, flow and electric field distribution in the heating cell. The mesh for $2 \mathrm{D}$ model was adapted until stable solution (grid independent solution) was achieved.

An iterative procedure was adopted to establish the profiles of temperature, velocity and electric field distribution of the fluids versus time during ohmic heating processing. Starting from an estimated initial temperature of the ohmic heating cell, the electrical conductivity, specific heat, thermal conductivity, viscosity and density were computed. The electric field and momentum equations were solved to obtain the velocity and the electric field distribution at steady state. The momentum, energy and electric field equations were solved and the associated properties were derived through iterations until a convergence value was reached for the solution. Convergence was attained by adjusting the number of elements and the time step as well as certain parameters related to successive substitution solver used.

\section{RESULTS}

Figure 2 shows the simulated $\mathrm{x}$-velocity profiles at different locations along the heating cell with buoyancy effect performed for guava juice. The flow velocity is higher at the center of the tube than in the region near the walls. It shows that near the entrance at $\mathrm{x}=0.1$ and $0.2 \mathrm{~m}$ the $x$-velocity was uniform at $0.003 \mathrm{~m} \mathrm{~s}^{-1}$ and jumped to $0.0035 \mathrm{~m} \mathrm{~s}^{-1}$ near the center. At the middle of the heating cell the velocity is drastically increased to $0.017 \mathrm{~m} \mathrm{~s}^{-1}$ at the region adjacent to the wall and dropped to zero at the region away from the wall. At location of $x=0.3 \mathrm{~m}$ the velocity was $0.024 \mathrm{~m} \mathrm{~s}^{-1}$ near the wall and dropped to zero at the region near the centre. At location $\mathrm{x}=0.04 \mathrm{~m}$ the velocity was $0.022 \mathrm{~m} \mathrm{~s}^{-1}$ and close to zero near the center. At locations 0.3 and $0.4 \mathrm{~m}$ reversed flow are clearly observed. At the exit of the heating cell the velocity dropped to $0.0013 \mathrm{~m} \mathrm{~s}^{-1}$ near the wall and decreased to $0.0015 \mathrm{~m} \mathrm{~s}^{-1}$ at the center.

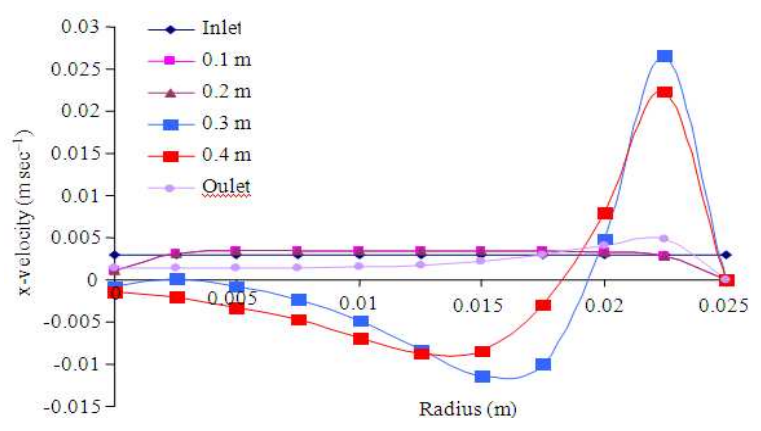

Fig. 2: x-velocity of guava juice with buoyancy effect 
Am. J. Applied Sci., 6 (11): 1902-1908, 2009

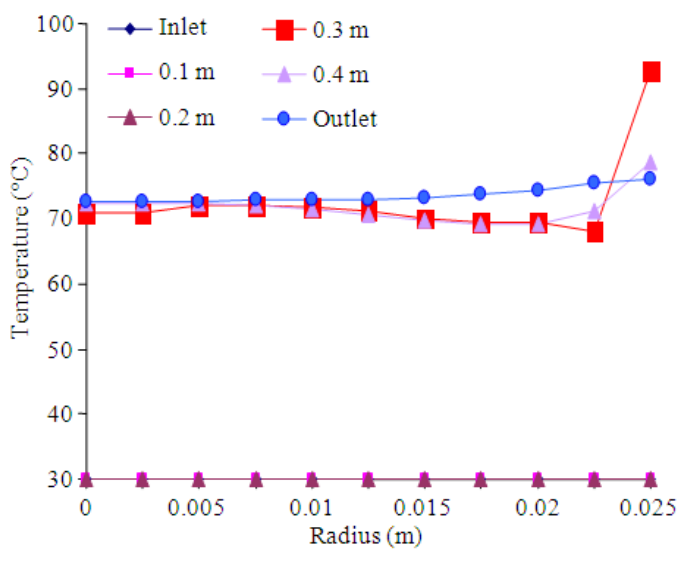

Fig. 3: Steady state temperature profiles of guava juice with buoyancy effect

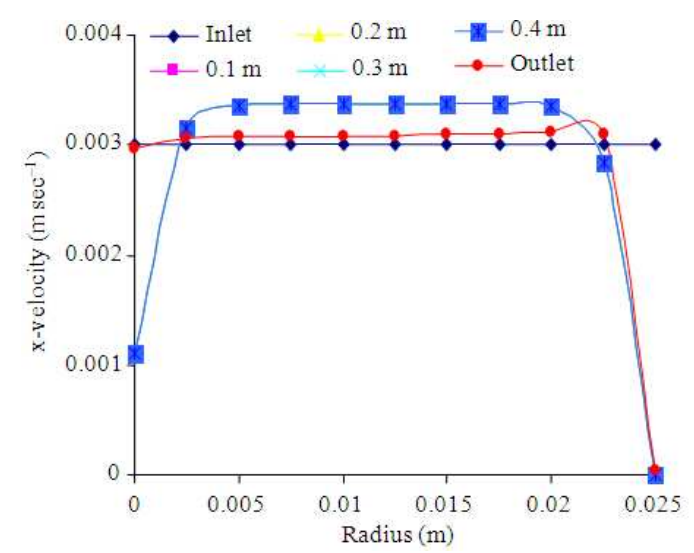

Fig. 4: x-velocity profiles of guava juice without buoyancy effect

Figure 3 shows the simulated temperature profiles with the incorporation of buoyancy effect. At region near the entrance $(\mathrm{x}=0.1$ and $0.2 \mathrm{~m})$ the temperature profiles has the same value of inlet temperature. When current density increases both the flow and temperature distributions began to change and the temperature at the location of $\mathrm{x}=0.3 \mathrm{~m}$ increased to $95{ }^{\circ} \mathrm{C}$ near the wall and $72{ }^{\circ} \mathrm{C}$ in the region away from the wall. Near the outlet at $\mathrm{x}=0.4 \mathrm{~m}$ the temperature is uniform at $81^{\circ} \mathrm{C}$ near the wall and $73{ }^{\circ} \mathrm{C}$ in the region away from the wall. At the outlet more uniform temperature was achieved, 80 ${ }^{\circ} \mathrm{C}$ near the wall and $75^{\circ} \mathrm{C}$ away from the wall.

Figure 4 shows the simulated velocity profiles in the absence of buoyancy effect. The velocity profiles were not distorted from the center to the walls. The velocity and temperature fields were coupled, and overheating was observed near the wall and under heating near the center as shown in Fig. 5.

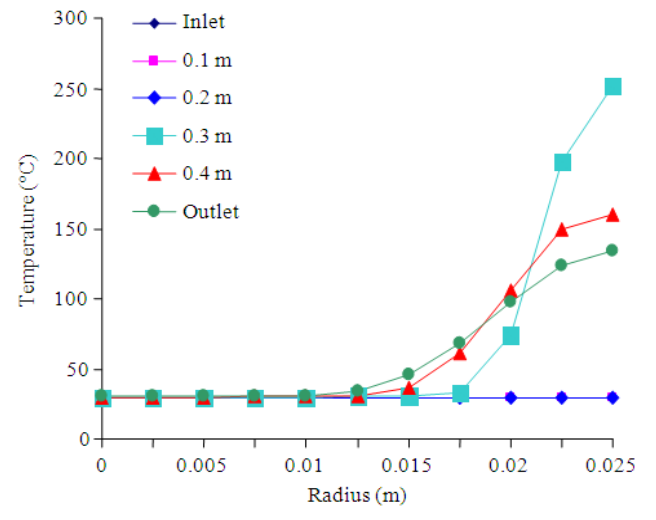

Fig. 5: Temperature profiles of guava juice without buoyancy effect

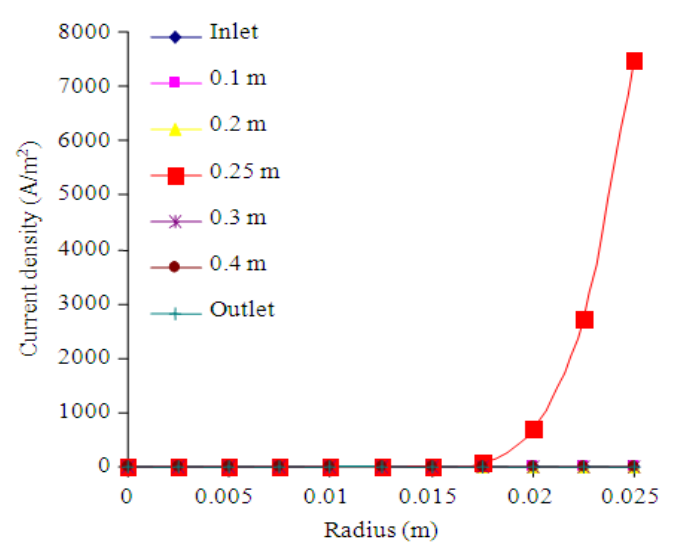

Fig. 6: Current density of guava juice with buoyancy effect

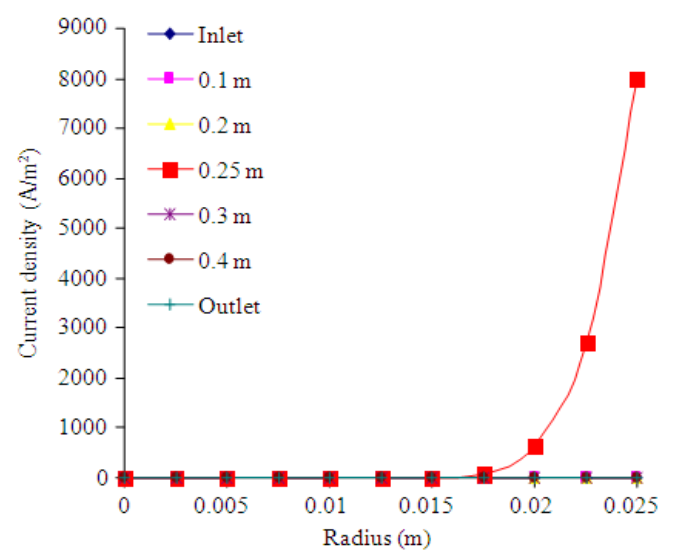

Fig. 7: Current density of guava juice without buoyancy effect

Figure 6 shows the simulated current density distributions inside the heating cell. The patterns appear 
to be of longitudinal configuration (or constant electric field), in which the product flows parallel to the electric field. However the current density shows maximum value $\left(6800 \mathrm{~A} / \mathrm{m}^{2}\right)$ at the surface of the middle electrode with buoyancy effect taking into consideration. However, when the buoyancy effect was not considered the current density was $7800 \mathrm{~A} / \mathrm{m}^{2}$ as shown in Fig. 7 .

\section{DISCUSSION}

The fluid passing in the region near the walls remain longer under the influence of the electric field and received more heating than those fluids passing in the center of the tube. The difference in the residence time causes a temperature difference between the center of the flow and the region near the walls. This temperature gradient is growing with the progressive of the heating of the liquid passes inside the tube so buoyancy effect is important and was taken into account. The buoyancy driving force is caused by density differences within the liquid due to spatial temperature variation between the wall and center. It distorts the velocity profiles and increased to the maximum value of the velocity from the center to near walls of the heating cell. Because the density and the viscosity of the fluids decreased with increasing temperature near the region of the walls there is generally an increase in velocity. It is apparent that the temperature increased along the axial coordinate. The highest temperature was observed near the wall at the middle of the heating cell because of the high value of the current density. The temperature at $\mathrm{x}=0.4 \mathrm{~m}$ and at the outlet was uniform. Since the Richardson number, $\mathrm{Gr}_{\mathrm{EL}} / \mathrm{Re}^{2}>1$, so a more realistic numerical model must consider the buoyancy effect. In the two cases mentioned above the maximum current density was below the critical value $8000 \mathrm{~A} / \mathrm{m}^{2[17]}$.

\section{CONCLUSION}

A steady-state two-dimensional cylindrical continuous ohmic heating of non-Newtonian fluid (guava juice) has been simulated by solving numerically the partial differential equations for continuity, momentums, energy and electric field. The results show that buoyancy effect distorted the velocity significantly, with reverse flow clearly observed. This provided better mixing in the cell which resulted in a more uniform temperature distribution compared to simulations which ignore the buoyancy effect. The CFD simulation also demonstrated that maximum current density at the middle electrode was below the critical value $8000 \mathrm{~A} / \mathrm{m}^{2}$.

\section{REFERENCES}

1. Stirling, R., 1987. Ohmic heating-a new process for the food industry. J. Power Eng., 6: 365- 371. http://scitation.aip.org/getabs/servlet/GetabsServlet ?prog=normal\&id=PEJOEE000001000006000365 $000001 \&$ idtype $=$ cvips \& gifs $=$ yes

2. Ayadi, M.A., J.C.F. Leuliet, F. Chopard, M. Berthou and M. Lebouche, 2005. Experimental study of hydrodynamics in flat ohmic cell-impact on fouling by dairy products. J. Food Eng., 70: 489-498. http://cat.inist.fr/?aModele $=$ afficheN\&cpsidt $=1686$ 0928

3. Sastry, S.K., A. Yousef, H.Y. Cho, R. Un S. Salengke, W-C. Wang, M. Lima, S. Kulshrestha 2001. Ohmic Heating and Moderate Electric Field (MEF) Processing. In: Engineering and Food for the 21st Century. Technomic Publishers. http://www.crcpress.com/product/isbn/9781566769 631

4. Lima, M. and S.K. Sastry, 1999. The effects of ohmic heating frequency on hot-air drying rate and juice yield. J. Food Sci., 41: 115-119. http://cat.inist.fr/?aModele $=$ afficheN\&cpsidt $=1996$ 783

5. Sun, 2007. Computational Fluid Dynamics in Food Processing. CRC Press Taylor and Francis Group, Boca Raton, London and New York, ISBN: 0849392861, pp: 739.

6. Jaiswal, U. and V.S. Jaiswal, 2005. Psidium Guajava. In: Biotechnology of Fruit and Nut Crops, Litz, R.E. (Ed.). CAB International, Wallingford, UK., pp: 394-401

7. Leite, K.M.S.C., A.C. Tadiotti, D. Baldochi and O.M.M.F. Oliveira, 2006. Partial purification, heat stability and kinetic characterization of the pectinmethylesterase from Brazilian guava, Paluma cultivars. Food Chem., 94: 565-572. http://cat.inist.fr/?aModele $=$ afficheN\&cpsidt $=1750$ 8022

8. Vikram, V.B., M.N. Ramesh and S.G. Prapulla, 2005. Thermal degradation kinetics of nutrients in orange juice heated by electromagnetic and conventional methods. J. Food Eng., 69: 31-40. DOI: 10.1016/J.JFOODENG.2004.07.013

9. Benabderrahmane, Y. and J.P. Pain, 2000. Thermal behaviour of a solid-liquid mixture in an ohmic heating sterilizer-slip phase model. Chem. Eng. Sci., 55: 1371-1384.

http://cat.inist.fr/?aModele $=$ afficheN\&cpsidt $=1234$ 419 
10. De Alwis, A.A.P., K. Halden and P.J. Fryer, 1989. Shape and conductivity effects in the ohmic heating of foods. Chem. Eng. Res. Des., 67: 159-168. http://archive.icheme.org/cgibin/somsid.cgi?type=header\&record=1999

11. Eliot-Godéreaux, S., F. Zuber and A.Goullieux, 2001. Processing and stabilization of cauliflower by ohmic heating technology. Innovat. Food Sci. Emerg. Technol., 2: 279-287. DOI: 10.1016/S1466-8564(01)00047-9

12. Fryer, P.J. and A. De Alwis, 1989. Validation of the APV ohmic heating process. Chem. Ind., 16: 630-634.

http://findarticles.com/p/articles/mi_hb5255/is_n19 /ai_n28586588/

13. Sudhir, K., S.K. Sastry and S. Salengke, 1998. Ohmic heating of solid-liquid mixtures: A comparison of mathematical models under worstcase heating conditions. J. Food Process Eng., 21: 441-458.

http://cat.inist.fr/?aModele $=$ afficheN\&cpsidt $=1728$ 928

14. Wadad, G., Khalaf, K. Sudhir and S.K. Sastry, 1996. Effect of fluid viscosity on the ohmic heating rate of solid-liquid mixtures. J. Food Eng., 27: 145-158. http://cat.inist.fr/?aModele $=$ afficheN\&cpsidt $=2945$ 895

15. Marcotte, M., 1999. Ohmic heating of viscous liquid food. Ph.D. Thesis, Department of Food Science and Agricultural Chemistry. University Mc Gill, Canada.

http://digitool.library.mcgill.ca:8881/R/?func=dbin -jump-full\&object_id=36036\&local_base=GEN01MCG02
16. Ould El Moktar, A., 1992. Investigation of coupled physical phenomena in heating by direct electric conduction of flowing ionic fluids. Ph.D. Thesis, Nancy I University, France. http://cat.inist.fr/?aModele $=$ afficheN\&cpsidt $=1520$ 13

17. Ghani, A.G., M.M. Farid and X.D. Chen, 2002. Numerical simulation of transient temperature and velocity profiles in a horizontal can during sterilization using computational fluid dynamics. J. Food Eng., 51: 77-83. DOI: 10.1016/S02608774(01)00039-5

18. Kronig, R. and G. Ahsmann, 1951. The influence of an electric field on the convective heat transfer in Liquids. Applied Sci. Res. Section A., 2: 31-32. DOI: 10.1007/BF00411971

19. Stirling, R., 1987. Ohmic heating-a new process for the food industry. J. Power Eng., 6: 365- 371. http://scitation.aip.org/getabs/servlet/GetabsServlet ?prog=normal\&id=PEJOEE000001000006000365 $000001 \&$ idtype $=$ cvips $\&$ gifs $=$ yes 